\title{
A parametric investigation of a PCM-based pin fin heat sink
}

\author{
R. Pakrouh ${ }^{1}$, M. J. Hosseini ${ }^{2}$, and A. A. Ranjbar ${ }^{1}$ \\ ${ }^{1}$ Department of Mechanical Engineering, Babol University of Technology, P.O. Box 484, Babol, Iran \\ ${ }^{2}$ Department of Mechanical Engineering, Golestan University, P.O. Box 155, Gorgan, Iran \\ Correspondence to: M. J. Hosseini (mj.hosseini@gu.ac.ir)
}

Received: 25 December 2014 - Revised: 29 April 2015 - Accepted: 2 May 2015 - Published: 19 May 2015

\begin{abstract}
This paper presents a numerical investigation in which thermal performance characteristics of pin fin heat sinks enhanced with phase-change materials (PCMs) designed for cooling of electronic devices are studied. The paraffin RT44 HC is poured into the aluminum pin fin heat sink container, which is chosen for its high thermal conductivity. The effects of different geometrical parameters, including number, thickness and height of fins, on performance are analyzed. Different aspects for heat transfer calculation, including the volume expansion in phase transition as well as natural convection in a fluid zone, are considered in the study. In order to validate the numerical model, previous experimental data and the present results are compared, and an acceptable agreement between these two is observed. Results show that increasing the number, thickness and height of fins leads to a significant decrease in the base temperature as well as operating time of the heat sink.
\end{abstract}

\section{Introduction}

Because of the fast development of modern technology and miniaturization of electronic packaging, new electronic devices generate a large amount of heat, which threatens their performance and efficiency. Therefore, thermal management of effective cooling systems has become one of the most important considerations in design of different pieces of electronic equipment. Considering the effects of temperature on the performance of electronic devices, an effective thermal design should be able to keep the working temperature of devices below their allowable maximum temperature during the entirety of normal operation.

There are common techniques, including air cooling, liquid cooling, piezoelectric pump and heat pipes, to remove high heat flux effectively from heat-generating electronic devices. Thermal energy storage, as a cooling method for electronic applications, is one of the techniques that have been widely researched in recent years. The thermal properties of some phase-change materials (PCMs), including meltingand solidification-related specifications, are listed by Abhat (1983). High latent heat of fusion, the capability of being a heat source at a constant temperature, and chemical stability are three of the favorite properties of PCMs. However these materials have the undesirable property of low thermal conductivity, which brings about a serious challenge in design application of PCM-based electronic cooling systems. In order to overcome this drawback, different techniques of enhancement have been proposed, including fins (Eftekhar et al., 1984; Henze and Humphrey, 1981), metal matrices (Ettouni et al., 2006) and nanoparticles (Ranjbar et al., 2011; Hosseini et al., 2013).

Several previous papers have studied the advantages of PCM utilization in electronic cooling systems. As reported by Pal and Joshi (2001), use of a PCM-based heat sink is an effective method for cooling of electronic devices. Kandasamy et al. (2007) in a combined experimental and numerical work studied the effects of various parameters such as power input level and the system configuration on PCM melting rate. Results showed that the geometrical shape of the package does not have a significant effect on the performance, while the input power influences the melting rate noticeably. Akhilesh et al. (2005) directed a numerical investigation to develop a thermal design procedure that maximizes the operating time of a composite heat sink which is made up of an elemental heat sink, PCM and high-conductivity base material. Hosseinizadeh et al. (2011) reported a parametric 
study on a plate fin PCM-based heat sink and found that increasing the number of fins and their height results in a considerable increase in overall thermal performance, whereas increasing the fins' thickness only brings about a slight improvement. Baby and Balaji (2012) compared the heat transfer performance of a plate fin heat sink with that of a pin fin heat sink in an experimental study. Their results showed that the pin fin heat sink exhibits a longer operation duration for electronic devices in comparison with similar plate fin heat sinks. Baby and Balaji (2013) experimentally developed an artificial neural network-genetic hybrid algorithm to determine the optimum configuration of a PCM-based pin fin heat sink in which the critical time is maximized. Shatikian et al. (2008) recommended a correlation among Nusselt, Stefan and Fourier numbers for a constant heat flux system. In their simulation, a complete formulation was endeavored which considers convection in the fluid zone and volume expansion of the PCM during phase transition. Nayak et al. (2006) studied a numerical model for PCM-based heat sinks with some different types of thermal conductivity enhancer (TCE) distribution. Their results showed that the use of TCE leads to a lower chip temperature. They also concluded that the convection in the melted PCM improves the temperature uniformity by increasing the effective heat transfer coefficient. Saha et al. (2010) presented a numerical investigation on melting of $n$-eicosane in a PCM-based plate fin heat sink to find the influence of the enclosure's aspect ratio on the performance of the system. They identified different non-dimensional numbers as effective parameters. They also have found a suitable length scale for each type of enclosure. Fok et al. (2010) experimentally investigated a PCM-based heat sink for cooling of portable hand-held electronic devices. They found that the orientation of the heat sink does not affect the heat sink performance meaningfully. Kozak et al. (2013) studied heat transfer as well as heat accumulation in a hybrid PCM-air heat sink both experimentally and numerically. The constant heat flux was applied to the bottom surface and the PCM subjected to a fan-driven forced convection. They have found that as the power input level increases, so too does the rate of sensible heat accumulation.

The present work evaluates the melting process of the PCM in the presence of pin-fin-type thermal conductivity enhancers (TCEs) for electronics cooling applications. The main purpose of this article is to investigate different effective parameters on the heat sink base temperature and melt fraction. The studied geometric parameters are the number of fins (for three values), fin thickness (for three values) and fin height (for two values).

\section{Numerical model}

\subsection{Governing equations}

The schematic diagram of the PCM-based pin fin heat sink is shown in Fig. 1. The heat sink is made of aluminum with
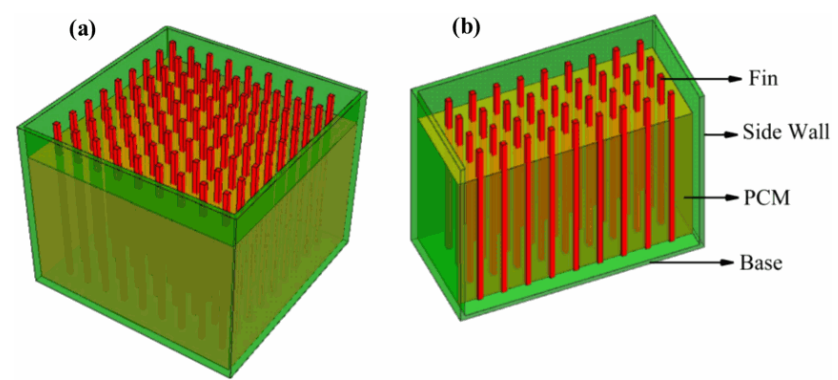

Figure 1. Example of a PCM-based pin fin heat sink: (a) actual geometry and (b) sectioned view.

Table 1. Numerical cases explored in this work.

\begin{tabular}{lccc}
\hline Case & $\begin{array}{c}\text { Fin height, } \\
H_{\mathrm{F}}(\mathrm{mm})\end{array}$ & $\begin{array}{c}\text { Number of } \\
\text { fins, } N\end{array}$ & $\begin{array}{c}\text { Fin thickness, } \\
w_{\mathrm{F}}(\mathrm{mm})\end{array}$ \\
\hline Case 1 & 15 & 25 & 2 \\
Case 2 & 15 & 25 & 4 \\
Case 3 & 15 & 25 & 6 \\
Case 4 & 15 & 49 & 6 \\
Case 5 & 15 & 100 & 6 \\
Case 6 & 25 & 25 & 2 \\
Case 7 & 25 & 25 & 4 \\
Case 8 & 25 & 25 & 6 \\
Case 9 & 25 & 49 & 6 \\
Case 10 & 25 & 100 & 6 \\
\hline
\end{tabular}

a different number of fins as well as different fin thicknesses, fin heights and base thicknesses. The dimensions of heat sink base are $70 \mathrm{~mm} \times 70 \mathrm{~mm}$. The base thickness is kept constant at $2 \mathrm{~mm}$. To simulate the heat revealed by the device, some elements are designated to generate $10.204 \mathrm{~kW} \mathrm{~m}^{-2}$. This heat-generating device, which is inserted under the bottom of the sink, requires $50 \mathrm{~W}$ of power. The sidewalls of the heat sink are merely there as preservative walls of the melted PCM and have no role in the heat transfer process. Thus the sidewalls are assumed to be adiabatic and it is supposed that the heat supplied to the system is transferred between the PCM and the heat transfer component of the device including the base, the fins and finally the surrounding air. A total of 10 different simulations, summarized in Table 1, with different geometrical dimensions are carried out in the present work. The commercial paraffin RT44 HC (Rubitherm GmbH, 2012) was used as the PCM. Table 2 shows the thermophysical properties of the material.

In order to simulate the melting process of the PCM, the enthalpy-porosity approach (Brent et al., 1988) is employed, wherein the porosity in each cell is set equal to the liquid fraction in that cell. In order to allow the PCM expansion during melting, the enclosure is filled to only $90 \%$ of the fin height and the remaining volume is occupied by air. $\mathrm{Nu}$ merical approaches, previously applied by other authors to heat sinks enhanced with plate fins (Shatikian et al., 2005; 
Table 2. Properties of materials employed in the present study.

\begin{tabular}{llllll}
\hline Material & $\rho\left(\mathrm{kg} \mathrm{m}^{-3}\right)$ & $k\left(\mathrm{~W} \mathrm{~m}^{-1} \mathrm{~K}^{-1}\right)$ & $C_{p}\left(\mathrm{~J} \mathrm{~kg}^{-1} \mathrm{~K}^{-1}\right)$ & $T_{m}\left({ }^{\circ} \mathrm{C}\right)$ & $\Delta H\left(\mathrm{~J} \mathrm{~kg}^{-1}\right)$ \\
\hline Paraffin RT44 & 780 (solid) & 0.2 & 2000 & $41-45$ & 255000 \\
& 760 (liquid) & & & & \\
Aluminum & 2719 & 202.4 & 871 & 660.4 & - \\
Air & $1.2 \times 10^{-5} T^{2}-0.01134 T+3.498$ & 0.0242 & 1006.4 & - & - \\
\hline
\end{tabular}

Kandasamy et al., 2007), considered a similar assumption to the expansion. A "volume-of-fluid" (VOF) model is used to solve the PCM-air system in which a moving internal interface is considered and interpenetration of the two fluids is disregarded (Hirts and Nichols, 1981). In this model, if the $n$th fluid's volume fraction in the computational cell is denoted as $\alpha_{n}$, then the following three conditions are possible:

$-\alpha_{n}=0$ the cell is empty of the $n$th fluid,

$-\alpha_{n}=1$ the cell is full of the $n$th fluid,

$-0<\alpha_{n}<1$ the cell contains the interface between the fluids.

Thus, the variables and properties in any given cell are either purely representative of one of the fluids or are a mixture of fluids, depending on their volume fraction values. For the air phase, the density depends on its temperature as shown in Table 2. Thus due to the compressibility of the air during melting, a compressible model is utilized.

For the aluminum base and fins, only a conduction mechanism is considered. Accordingly, the energy equation is

$$
\frac{\partial}{\partial t}\left(\rho_{\mathrm{A} 1} \hbar\right)=\frac{\partial}{\partial x_{i}}\left(k_{\mathrm{Al}} \frac{\partial T}{\partial x_{i}}\right),
$$

where $\hbar\left(\mathrm{J} \mathrm{kg}^{-1}\right)$ is the specific enthalpy and $k_{\mathrm{Al}}$ ( $\mathrm{W} \mathrm{m}^{-1} \mathrm{~K}^{-1}$ ) is the thermal conductivity of aluminum. Also, the governing equations used here for modeling the PCM-air system are

(a) continuity equation,

$$
\frac{D \alpha_{n}}{D t}=0
$$

(b) momentum equation,

$\rho \frac{D \boldsymbol{v}}{D t}=-\nabla P+\mu \nabla^{2} \boldsymbol{v}+\rho \boldsymbol{g}+\boldsymbol{S} ;$

(c) energy equation,

$\rho \frac{D \hbar}{D t}=k \nabla^{2} T$

where $\alpha_{n}$ is the $n$th fluid's volume fraction in computational cells. As shown in Table 2, a density-temperature relation is assumed for air. For the PCM portion, the density in liquid phase can be expressed as

$\rho=\frac{\rho_{l}}{\beta\left(T-T_{l}\right)+1}$,

where $\beta$ is the thermal expansion coefficient and is set to 0.001 , which is given in the study done by Humphries and Griggs (1977). The dynamic viscosity of the liquid PCM has been expressed as

$\mu=0.001 \times \exp \left(A+\frac{B}{T}\right)$,

where $A=-4.25$ and $B=1790$ are reported by Reid et al. (1987). $S_{n, i}$ is the momentum sink due to the reduced porosity in the mushy zone that takes the following form:

$\boldsymbol{S}=-\frac{C(1-\gamma)^{2}}{\left(\gamma^{3}+\varepsilon\right)} \boldsymbol{v}$

where $C(1-\gamma)^{2} /\left(\gamma^{3}+\varepsilon\right)$ is the mimic "porosity function" defined by Brent et al. (1988). The value of $C$ is the mushy zone constant, which measures the amplitude of the velocity damping, and is considered to be $C=10^{5}$ in the present study.

\subsection{Boundary and initial conditions}

In all simulations the initial temperature of the whole system is $T_{0}=27^{\circ} \mathrm{C}$. Heat transfer from the fin tips to the ambient is considered negligible. Considering the symmetry of the geometry and following Dubovsky et al. (2009), only onequarter of the fin horizontal cross section is included in the computation (Fig. 2). It is assumed that the distance between the exterior fins the and heat sink walls is half of the space between the fins; this assumption leads to a similar simulation for all the included fins. We note that the PCM layer's width $\left(w_{\mathrm{P}}\right)$ varies as the thickness $\left(w_{\mathrm{F}}\right)$ and number $\left(N_{\mathrm{F}}\right)$ of fins change. Table 3 presents the geometric variation of fin thickness and inter-fin distance.

The boundary conditions applied to the computational domain, in Fig. 2, are

(a) heat flux to the bottom,

$-\left.k_{\mathrm{Al}} \frac{\partial T}{\partial y}\right|_{y=0}=q^{\prime \prime}$ 
Table 3. Fin thickness and inter-fin distance for different fin numbers.

\begin{tabular}{lcccccccc}
\hline & $w_{\mathrm{F}}(\mathrm{mm})$ & $w_{\mathrm{P}}(\mathrm{mm})$ & & $w_{\mathrm{F}}(\mathrm{mm})$ & $w_{\mathrm{P}}(\mathrm{mm})$ & & $w_{\mathrm{F}}(\mathrm{mm})$ & $w_{\mathrm{P}}(\mathrm{mm})$ \\
\cline { 2 - 3 } \cline { 7 - 8 }$N_{\mathrm{F}}=25$ & 2 & 12 & & 4 & 10 & & 6 & 8 \\
$N_{\mathrm{F}}=49$ & 2 & 8 & & 4 & 6 & & 6 & 4 \\
$N_{\mathrm{F}}=100$ & 2 & 5 & & 4 & 3 & & 6 & 1 \\
\hline
\end{tabular}

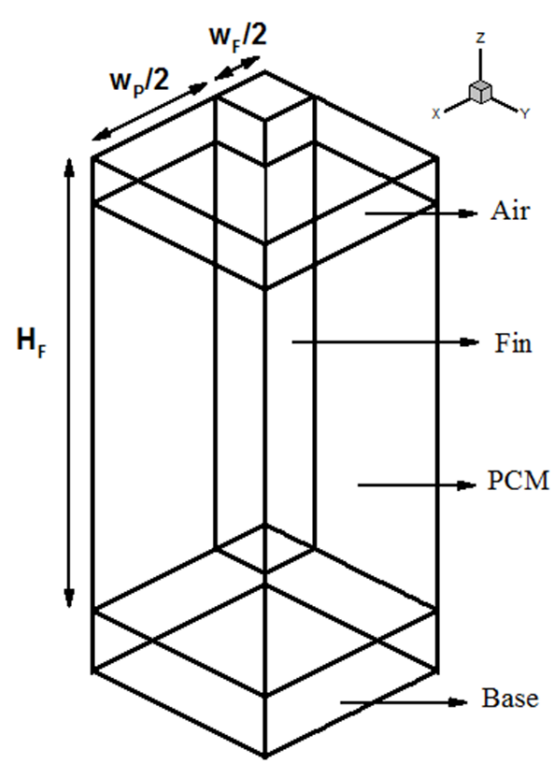

Figure 2. Schematic of the computational domain.

(b) symmetry boundary conditions at all enclosing sides,

$$
\frac{\partial T}{\partial x}=\frac{\partial T}{\partial y}=0, \frac{\partial u_{i}}{\partial x}=\frac{\partial u_{i}}{\partial y}=0 ;
$$

(c) adiabatic boundary condition at fins' tip,

$$
-k_{\mathrm{Al}} \frac{\partial T}{\partial y}=0
$$

\subsection{Numerical procedure and validation}

The SIMPLE algorithm within a 3-D in-house code (Rahimi et al., 2012) developed by authors was utilized for pressurevelocity coupling. The QUICK differencing scheme was adopted for solving the momentum and energy equations, whereas the PRESTO scheme was used for the pressure correction equation. The effects of time step and grid size on the solution were carefully examined in preliminary simulations. Therefore, the time step in the simulations is set to $0.005 \mathrm{~s}$. Different grid sizes are used in the simulations, varying from 9500 to 34000 cells for the fin height of $15 \mathrm{~mm}$, 15500 to 56000 cells for the height of $25 \mathrm{~mm}$, and 18500 to 74000 cells for the height of $35 \mathrm{~mm}$. It is noticeable that, for the same fin height, the population of denser fins requires a larger number of grid cells. The convergence is checked at

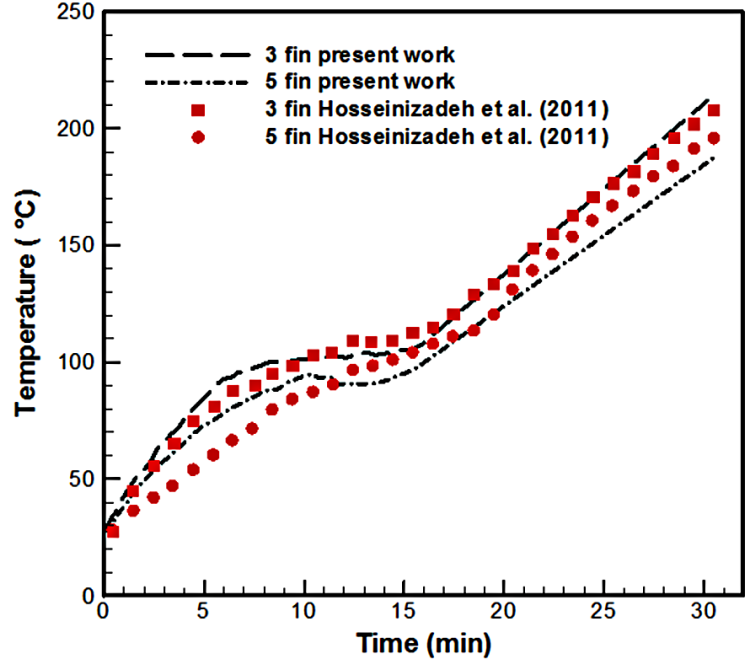

Figure 3. Comparison of base temperature profile between the present work and Hosseinizadeh et al. (2011).

each time step, with the convergence criterion of $10^{-6}$ for the continuity equation, $10^{-5}$ for the momentum equation and $10^{-8}$ for the energy equation. In order to validate the melting computational model in our finite-volume CFD code, initial runs were performed and compared with experimental data of Hosseinizadeh et al. (2011). As can be seen from Fig. 3, there is a good agreement between the present calculation and those calculations of Hosseinizadeh et al. (2011).

\section{Numerical results}

In this section, the results of the parametric study are presented and discussed. The analysis involves the PCM melt fractions and the base temperatures as functions of time, which is intended to explain the effect of the geometry variation on the thermal performance of the heat sink.

\subsection{Effect of number of fins}

Figures 4 and 5 present the melt fraction and base temperature as functions of time for different number of fins at various fin heights. As expected, for both fin heights of 15 and $25 \mathrm{~mm}$, the total melting time of the PCM decreases as the number of fins increases, as shown in Fig. $4 \mathrm{a}$ and b. This is due to the fact that the PCM volume decreases as the number 


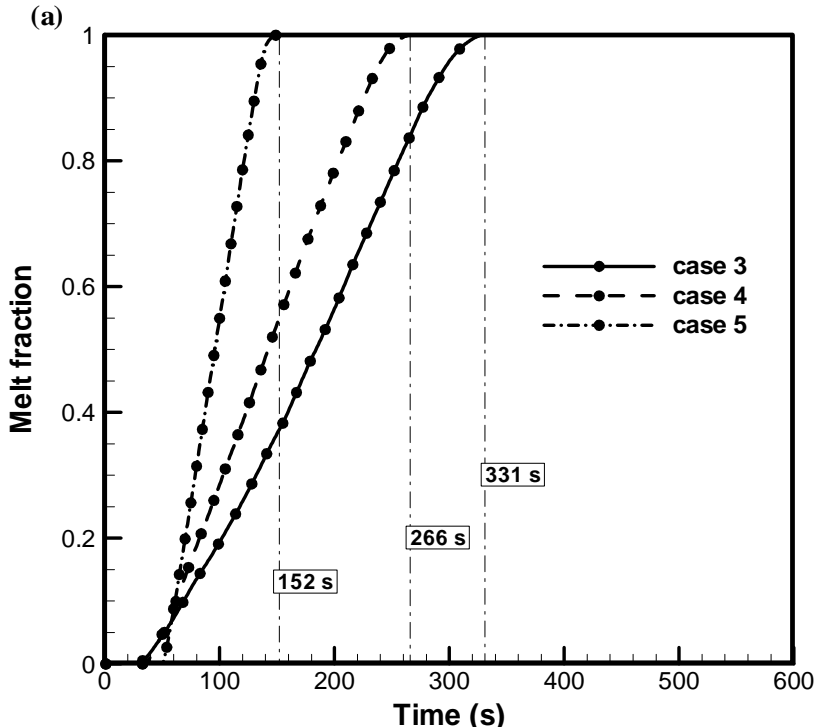

(b)

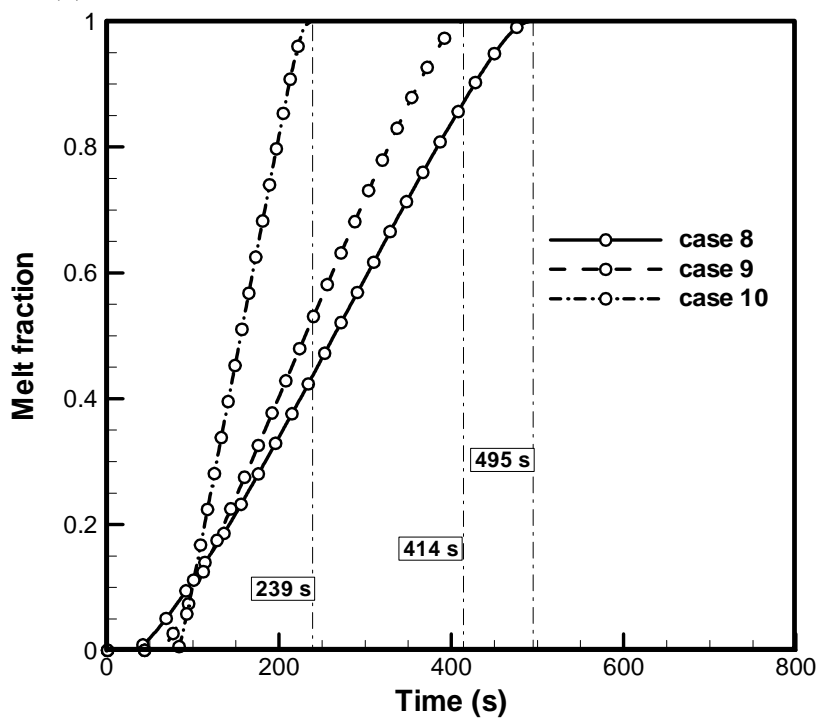

Figure 4. Melt fraction evolution with time for different numbers of fins: (a) various cases for fin height of $15 \mathrm{~mm}$ and (b) various cases for fin height of $25 \mathrm{~mm}$.

of fins rises. The lesser volume of the PCM leads to a latent heat potential reduction and thus a shorter melting period.

The effect of the number of fins is examined by checking the base temperature profiles in Fig. 5. It can be seen that the curves have similar forms and trends for both fin heights of 15 and $25 \mathrm{~mm}$. Because of the extra surface, 100 fins provide more heat storage capacity compared to 25 fins, so a lower base temperature is observed for a greater number of fins, i.e., a 100-fin unit has a lower base temperature compared to units with 49 and 25 fins. It should be noted that although the base temperature decreases as the number of fins increases (which is significantly effective in electronics cooling systems), the latent heat period (which maintains
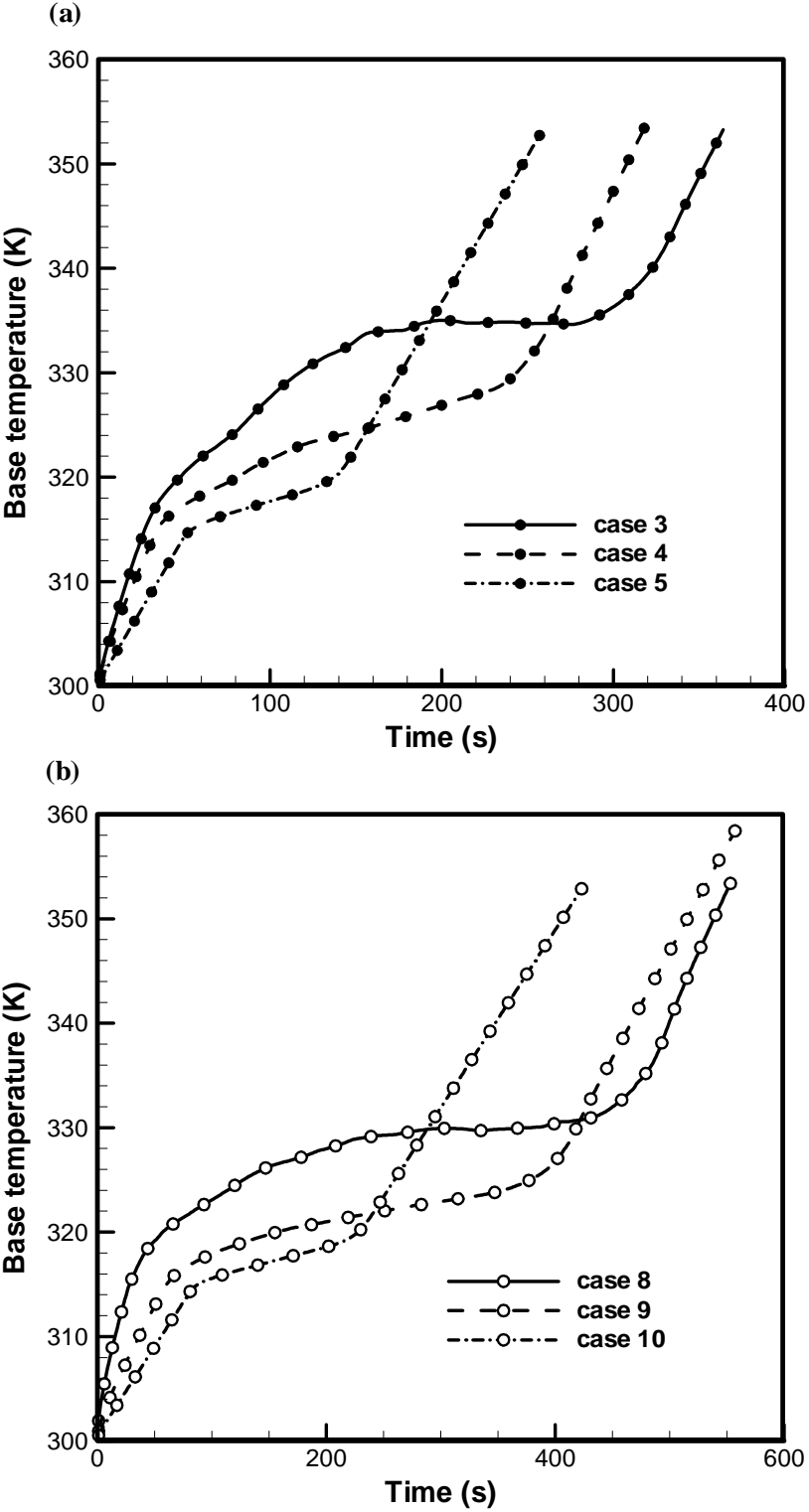

Figure 5. Base temperature evolution with time for different numbers of fins: (a) various cases for fin height of $15 \mathrm{~mm}$ and (b) various cases for fin height of $25 \mathrm{~mm}$.

the base temperature within a specified and almost constant range) decreases. For instance, in Fig. 5b, the latent heat period for heat sinks with 25,49 and 100 fins is about 392,310 and $138 \mathrm{~s}$, respectively. As mentioned earlier, this is due to the decrease in the latent heat capacity of the system while the number of fins increases.

\subsection{Effect of fin thickness}

Figure 6 shows the melt fraction versus time for different pin fin thicknesses. As can be seen, the total melting time of PCM decreases as fin thickness increases. As mentioned, this is because the smaller PCM volume provides a lower 


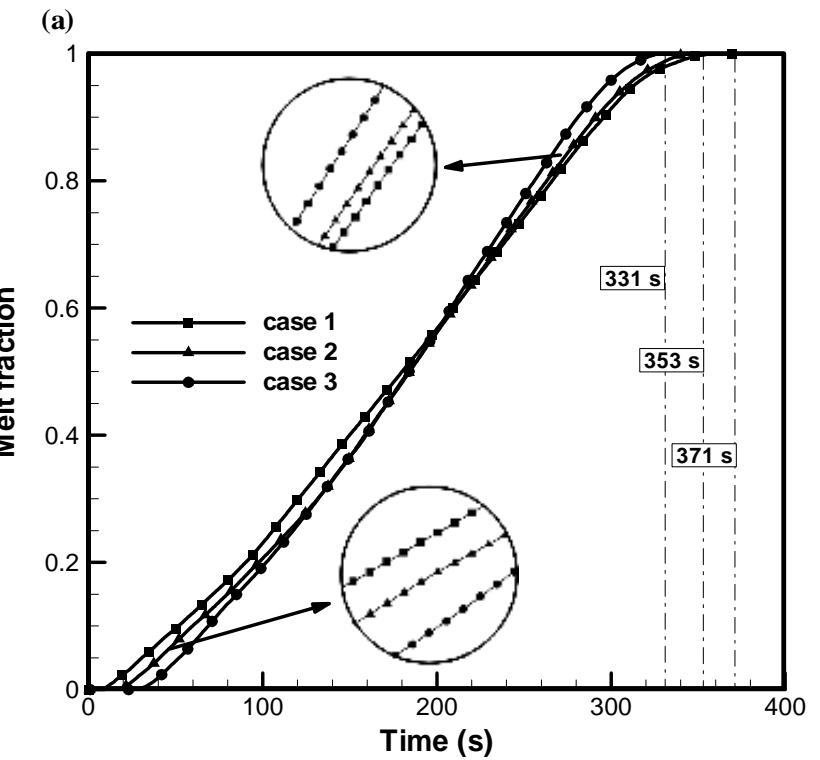

(b)

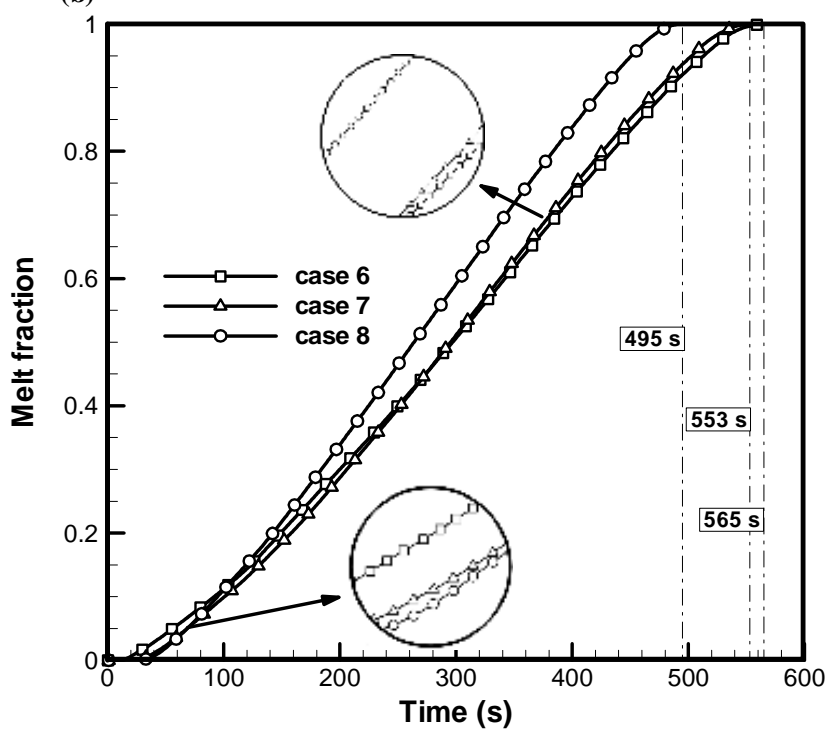

Figure 6. Melt fraction evolution with time for different fin thicknesses: (a) various cases for fin height of $15 \mathrm{~mm}$ and (b) various cases for fin height of $25 \mathrm{~mm}$.

latent heat absorption capacity. Second, the initiation of the PCM melting occurs later as the fins become thicker. This behavior was first observed by Hosseinizadeh et al. (2011) for PCM-based plate fin heat sinks. Their results showed that this property is related to the mode of heat transfer in the PCM, and heat is mainly transferred by conduction. According to Fourier's law $\left(q^{\prime \prime}=-k \nabla T\right)$, the conduction is related to the temperature gradient. This means that a higher temperature gradient results in greater heat conduction. In the present study the fins with $2 \mathrm{~mm}$ thickness give the higher temperature gradient compared to those of 4 and $6 \mathrm{~mm}$ thickness, and as we can see, a faster onset of the melting process is achieved in Fig. 6a and b.
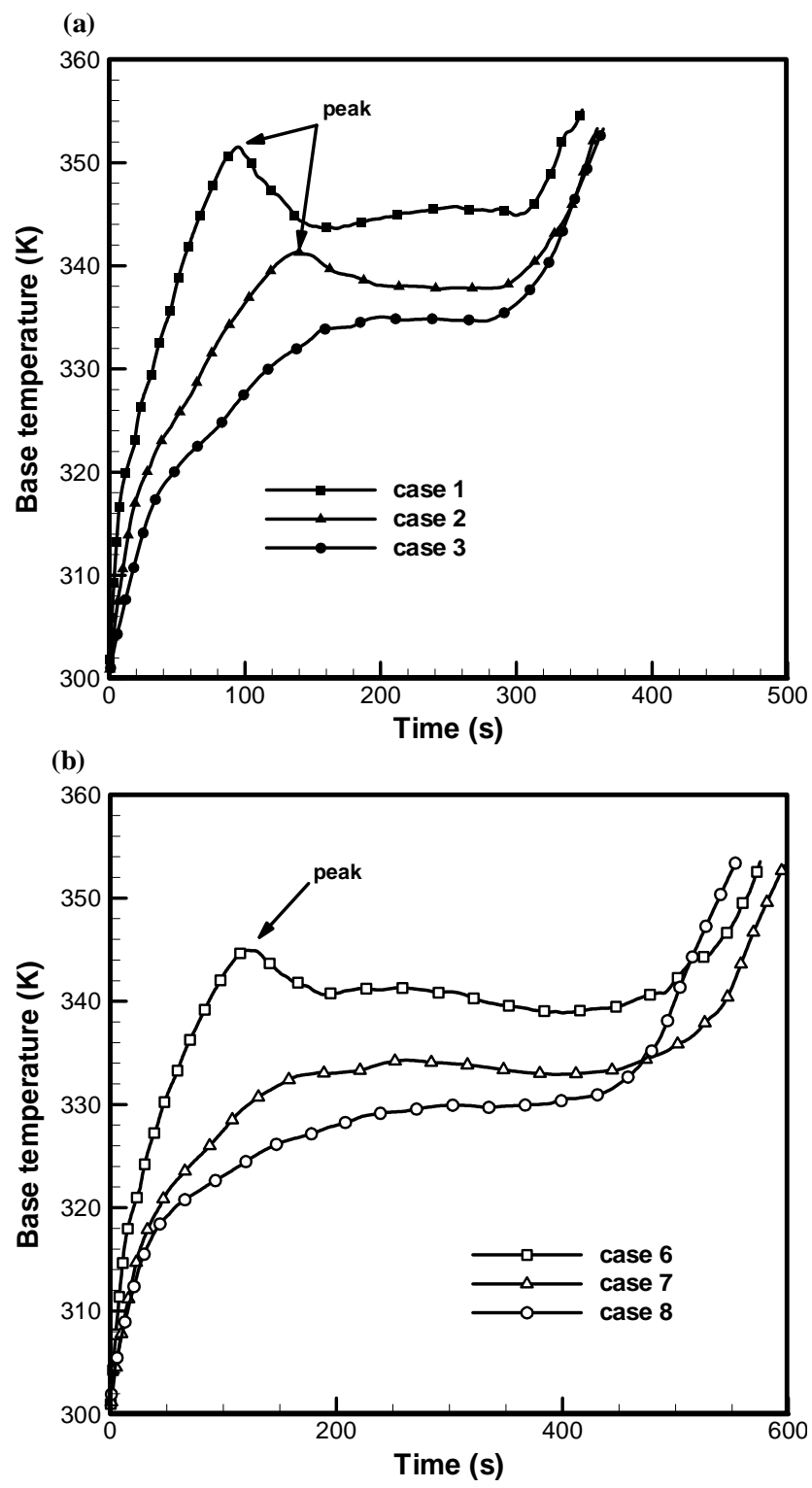

Figure 7. Base temperature evolution with time for different fin thicknesses: (a) various cases for fin height of $15 \mathrm{~mm}$ and (b) various cases for fin height of $25 \mathrm{~mm}$.

Figure 7 compares the base temperature profiles for various fin thicknesses. It can be seen that, with increasing fin thickness, the base temperature decreases considerably during the latent heat period. For instance, case 1 exhibits a lower temperature than cases 2 and 3 by about 8 and $10 \mathrm{~K}$ respectively.

From Fig. 7, it can be observed that fast growth of the base temperature causes a peak in the profiles of thinner fins. In other words, due to the low heat capacity of the thinner fins, the base temperature rises rapidly at the early stages of melting. As the effect of natural convection increases, the flow circulation results in a local decrease in base temperature. 


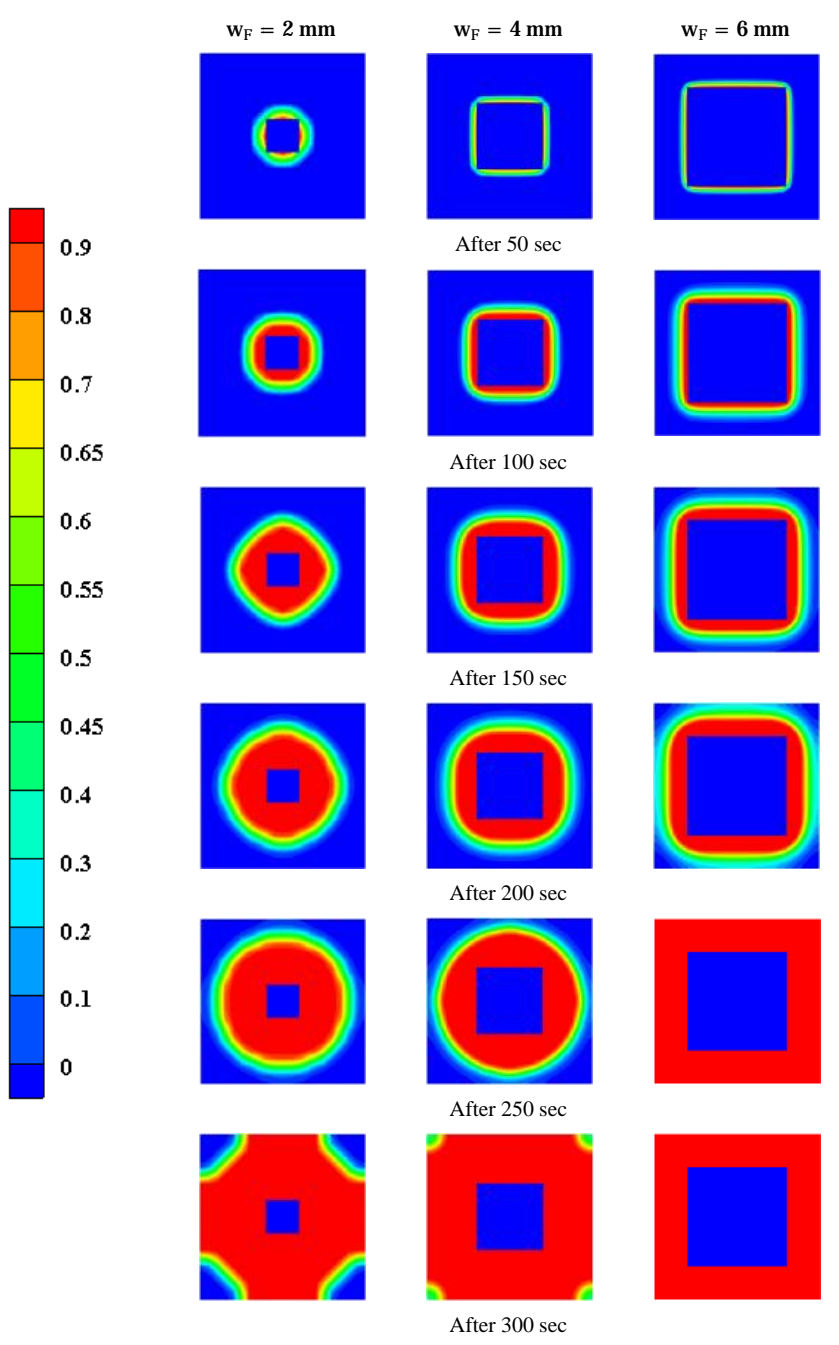

Figure 8. Melt fraction distribution for 49 fins and various fin thicknesses.

But for thicker fins, due to the high heat capacity of the system, heat is distributed uniformly and thus the base temperature curves are flattened. We can see that various fin thicknesses in Fig. 7b have smoother profiles compared to those in Fig. 7a. For example, the $4 \mathrm{~mm}$ thick fin of $15 \mathrm{~mm}$ fin height (case 2) includes the peak, but no peak is observed for that of $25 \mathrm{~mm}$ fin height (case 7).

Figure 8 shows plan view of the melt front evaluation with time for different fin thicknesses at half-height of the fin. As can be seen, in all cases the melting process starts at the four sidewalls of the fins. Over time, more of the PCM melts, and at final stages of melting processes, the liquid regions formed around the fins connect to each other. Temperature contours corresponding to Fig. 8 are given in Fig. 9. It is worth mentioning that, before $250 \mathrm{~s}$, the thicker fin $\left(w_{\mathrm{F}}=6 \mathrm{~mm}\right)$ leads to a lower temperature compared to thinner ones $\left(w_{\mathrm{F}}=4\right.$, $2 \mathrm{~mm}$ ). After $250 \mathrm{~s}$ the temperature of the thicker fins rises to a large value. This is due to the fact that all of the PCM is liq-

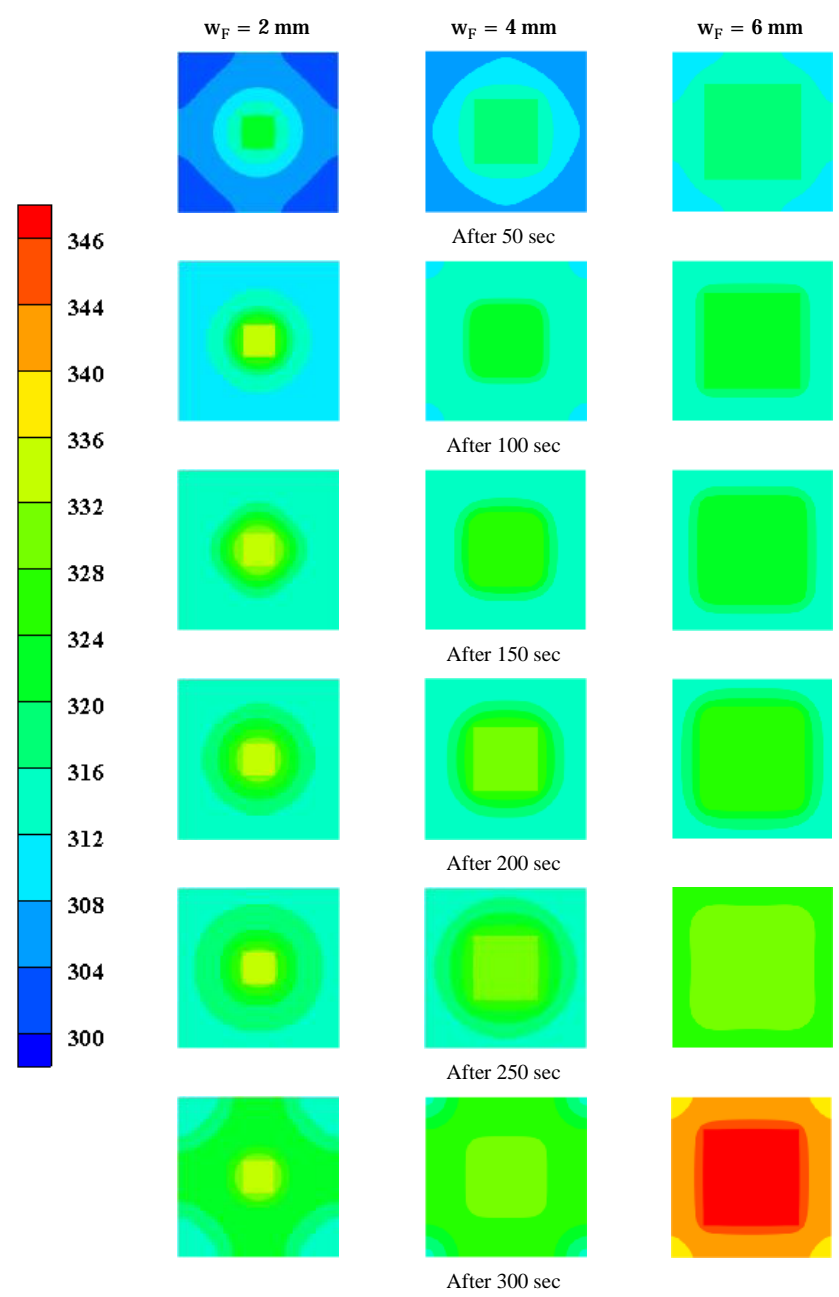

Figure 9. Temperature evolution for 49 fins and various fin thicknesses.

uid after $250 \mathrm{~s}$, i.e., all the latent heat capacity of the system has been actualized, and hence the fin temperature increases more quickly.

As previously mentioned, the present work considers the effect of natural convection in the liquid PCM. Figure 10 deals with this subject for the wide case, case 6 , and the narrow case, case 9 . The right- and left-hand slices show the temperature evolution and velocity fields, respectively. As can be seen, in case 6, which contains a thick layer of PCM, the flow is trivial at a melt fraction of 0.1 but it becomes powerful at a melt fraction of 0.6. However, in case 9, which has a relatively thinner layer of PCM, the velocity field is weak even at a melt fraction of 0.6. This figure implies that the natural convection in the molten PCM depends on both the melt fraction and the geometrical characteristics of the heat sink. It should be noted that the strongest flow field is observed in the air region due to the lower density of air compared to that of liquid PCM. Figure 10 also shows that the use of 


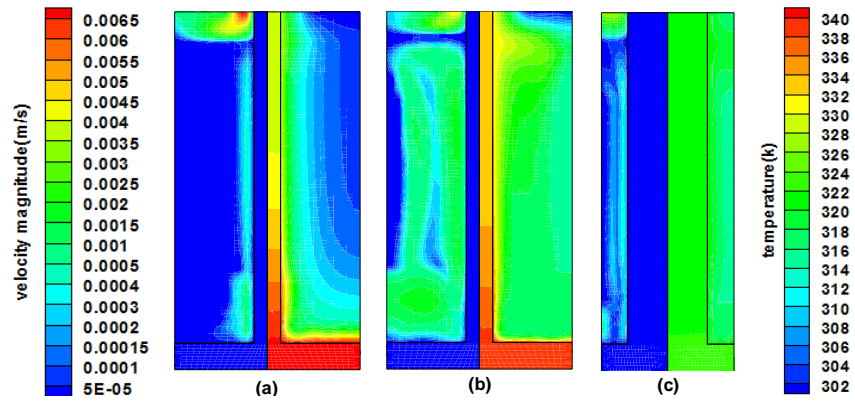

Figure 10. Temperature evolution and velocity fields: (a) case 6 and melt fraction of 0.1 , (b) case 6 and melt fraction of 0.6 , and (c) case 9 and melt fraction of 0.6 .

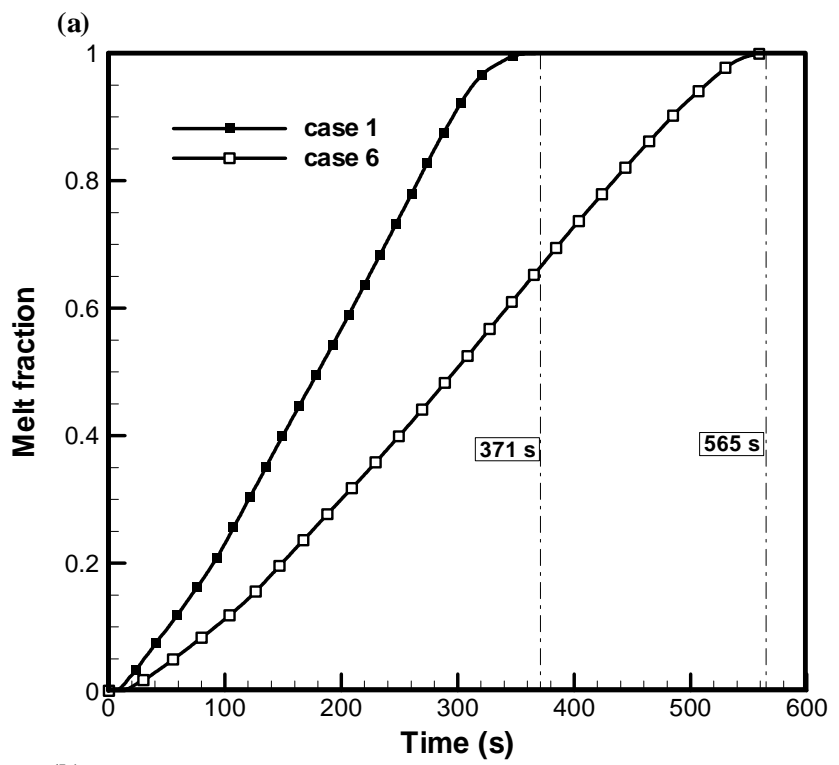

(b)

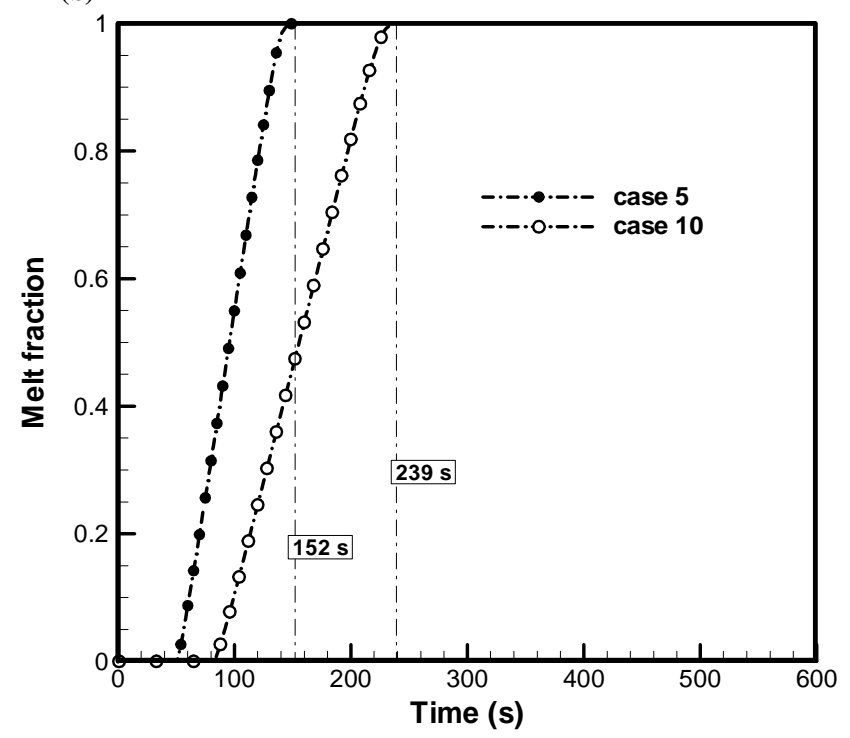

Figure 11. Melt fraction evolution with time for different fin heights: (a) various cases for 25 fins and $w_{\mathrm{F}}=2 \mathrm{~mm}$ and (b) various cases for 100 fins and $w_{\mathrm{F}}=6 \mathrm{~mm}$.
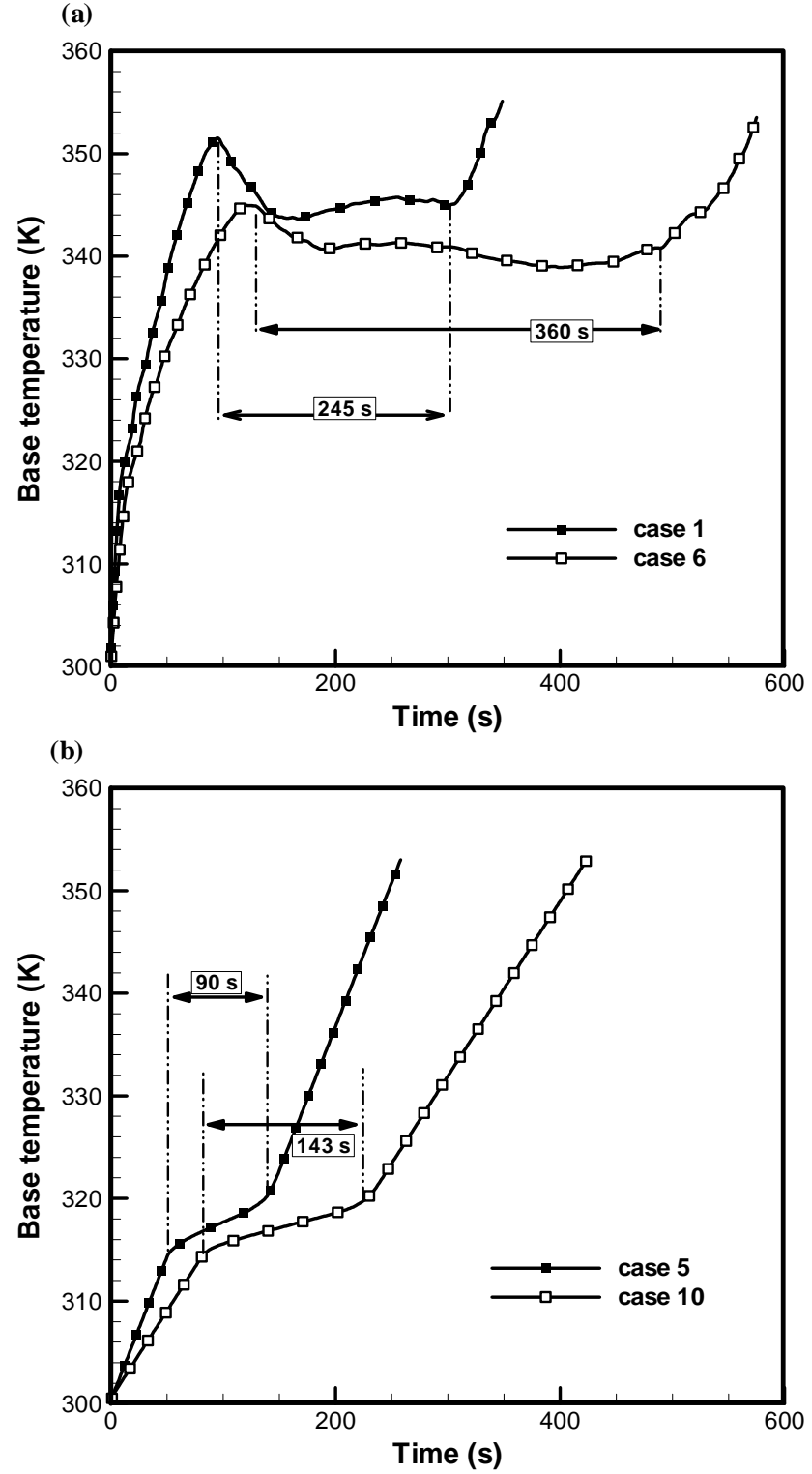

Figure 12. Base temperature evolution with time for different fin heights: (a) various cases for 25 fins and $w_{\mathrm{F}}=2 \mathrm{~mm}$ and (b) various cases for 100 fins and $w_{\mathrm{F}}=6 \mathrm{~mm}$.

thick fins causes a more uniform temperature distribution in the system.

\subsection{Effect of fin height}

Figure 11 shows the melt fraction versus time for two fin heights. As expected, the total melting time increases with increasing fin height, e.g., from 371 to $565 \mathrm{~s}$ for cases 1 and 6 . This is because of the large amount of PCM in the enclosure designed for the higher fins of the heat sinks. This observation is contrary to the results obtained by Hosseinizadeh et al. (2011) for plate fin heat sinks. This is due to the fact that, in their study, the height of the heat sink and consequently 
the amount of PCM content is assumed fixed, whereas in this study the heights of the heat sink and the fins are equal to each other. Therefore the PCM content increases as the fin height increases.

Figure 12 presents the temperature evaluation for the cases in Fig. 11. From this figure it can be seen that, for longer fins, the temperature growth is slower than that of the shorter fins, and thus the average temperatures of the heat sink are less. Furthermore, the latent heat period of the system in which the base temperature remains almost constant increases.

\section{Conclusions}

The use of PCMs in electronics cooling systems has been of increasing interest to researchers in recent years. Increasing the number of fins leads to a lower melting time. This is because of the fact that, by increasing the number of fins, the heat storage capacity of the system increases while the PCM volume decreases.

The total melting time of the PCM reduces when initiation of the PCM melting processes is delayed due to increased fin thickness. Finally, taller fins result in a lower melting time and lower base temperature. It can be concluded that increasing the number of fins as well as the fin thickness and height results in a lower base temperature, which means a lower chip temperature.

Edited by: A. Barari

Reviewed by: two anonymous referees

\section{References}

Abhat, A.: Low temperature latent heat thermal energy storage: heat storage materials, Sol. Energy, 30, 313-332, 1983.

Akhilesh, R., Narasimhan, A., and Balaji, C.: Method to improve geometry for heat transfer enhancement in PCM composite heat sinks, Int. J. Heat Mass Tran., 48, 2759-2770, 2005.

Baby, R. and Balaji, C.: Experimental investigations on phase change material based finned heat sinks for electronic equipment cooling, Int. J. Heat Mass Tran., 55, 1642-1649, 2012.

Baby, R. and Balaji, C.: Thermal optimization of PCM based pin fin heat sinks: An experimental study, Appl. Therm. Eng., 54, 65-77, 2013.

Brent, A. D., Voller, V. R., and Reid, K. J.: Enthalpy-porosity technique for modeling convection-diffusion phase change: application to the melting of a pure metal, Numer. Heat Tr. B-Fund., 13, 297-318, 1988.

Dubovsky, V., Barzilay, G., Granot, G., Ziskind, G., and Letan, R.: Study of PCM-based pin-fin heat sinks, Proceedings of the ASME Heat Transfer summer conference, San Francisco, California, USA, 2009.

Eftekhar, J., Haji-Sheikh, A., and Lou, D. Y. S.: Heat Transfer Enhancement in a Paraffin Wax Thermal Storage System, J. Sol. Energ.-T. ASME, 106, 299-306, 1984.

Ettouney, H., Alatiqi, I., Al-Sahali, M., and Al-Hajirie, K.: Heat transfer enhancement in energy storage in spherical capsules- filled with paraffin wax and metal beads, Energ. Convers. Manage., 47, 211-228, 2006.

Fok, S. C., Shen, W., and Tan, F. L.: Cooling of portable hand-held electronic devices using phase change materials in finned heat sinks, Int. J. Therm. Sci., 49, 109-117, 2010.

Henze, H. R. and Humphrey, J. A. C.: Enhanced heat conduction in phase-change thermal energy storage devices, Int. J. Heat Mass Tran., 24, 459-474, 1981.

Hirt, C. and Nichols, B.: Volume of fluid (VOF) method for the dynamics of free boundaries, J. Comput. Phys., 39, 201-225, 1981.

Hosseini, M. J., Ranjbar, A. A., Sedighi, K., and Rahimi, M.: Melting of Nanoprticle-Enhanced Phase Change Material inside Shell and Tube Heat Exchanger, Hindawi Publishing Corporation, Journal of Engineering, 2013, 784681, doi:10.1155/2013/784681, 2013.

Hosseinizadeh, S. F., Tan, F. L., and Moosania, S. M.: Experimental and numerical studies on performance of PCM-based heat sink with different configurations of internal fins, Appl. Therm. Eng., 31, 3827-3838, 2011

Humphries, W. and Griggs, E.: A design handbook for phase change thermal control and energy storage devices, Tech. rep., 1074NASA Scientific and Technical Information Office, 1977.

Kandasamy, R., Wang, X., and Mujumdar, S.: Application of phase change materials in thermal management of electronics, Applied Thermal Energy, 27, 2822-2832, 2007.

Kozak, Y., Abramzom, B., and Ziskind, G.: Experimental and numerical investigation of a hybrid PCM-AIR heat sink, Appl. Therm. Eng., 59, 142-152, 2013.

Nayak, K. C., Saha, S. K., Srinivasan, K., and Dutta, P.: A numerical model for heat sinks with phase change materials and thermal conductivity enhancers, Int. J. Heat Mass Tran., 49, 1833-1844, 2006.

Pal, D. and Joshi, Y. K.: Melting in a side heated tall enclosure by a uniformly dissipating heat source, Int. J. Heat Mass Tran., 44, 375-387, 2001.

Rahimi, M., Ranjbar, A. A., Hosseini, M. J., and Abdollahzadeh, M.: Natural convection of nanoparticle-water mixture near its density inversion in a rectangular enclosure, Int. Commun. Heat Mass, 39, 131-137, 2012.

Ranjbar, A. A, Kashani, S., Hosseinizadeh, S. F., and Ghanbarpour, M.: Numerical heat transfer studies of a latent heat storage system containing nano-enhanced phase change material, Therm. Sci., 15, 169-181, 2011.

Reid, R., Prausnitz, J., and Poling, B.: The Properties of Gases and Liquids, McGraw-Hill, New York, 1987.

RUBITHERM: http://www.rubitherm.de/english/index.htm (last access: 18 February 2014), 2012.

Saha, S. K. and Dutta, P.: Heat transfer correlations for PCM-based heat sinks with plate fins, Appl. Therm. Eng., 30, 2485-2491, 2010.

Shatikian, V., Ziskind, G., and Letan, R.: Numerical investigation of a PCM-based heat sink with internal fins, Int. J. Heat Mass Tran., 48, 3689-3706, 2005

Shatikian, V., Ziskind, G., and Letan, R.: Numerical investigation of a PCM-based heat sink with internal fins: Constant heat flux, Int. J. Heat Mass Tran., 51, 1488-1493, 2008. 